\title{
Establishment of reference values for complete blood count and blood gases in cynomolgus monkeys (Macaca fascicularis)
}

\author{
Shunya NAKAYAMA ${ }^{1,2)}$, Hiroshi KOIE ${ }^{1)}$, Kiichi KANAYAMA ${ }^{1)}$, Yuko KATAKAI ${ }^{3)}$, \\ Yasuyo ITO-FUJISHIRO ${ }^{1,2)}$, Tadashi SANKAI ${ }^{2)}$, Yasuhiro YASUTOMI ${ }^{2,4)}$ and \\ Naohide AGEYAMA ${ }^{2) *}$ \\ ${ }^{1)}$ Nihon University, Collage of Bioresource Science, Kanagawa 252-0880, Japan \\ 2) Tsukuba Primate Research Center, National Institutes of Biomedical Innovation, Health and Nutrition, \\ Ibaraki 305-0843, Japan \\ 3)The Corporation for Production and Research of Laboratory Primates, Ibaraki 305-0003, Japan \\ 4) Mie University Graduate School of Medicine, Department of Molecular and Experimental Medicine, \\ Mie 514-8507, Japan
}

\section{J. Vet. Med. Sci.}

79(5): 881-888, 2017

doi: 10.1292/jvms.16-0638

Received: 22 December 2016 Accepted: 3 March 2017 Published online in J-STAGE: 1 April 2017
ABSTRACT. Cynomolgus monkeys are closely related to humans phylogenetically, and this has resulted in their widespread use as a preclinical model. Hematological data with regard to these monkeys are thus important. Although reference values for blood components and sex hormones have been established for cynomolgus monkeys, those for arterial blood gases have not. The arterial blood gases quickly reflect respiratory and circulatory dynamics, and are thus useful for animal management and safe general anesthesia and surgical operations. Furthermore, since $\mathrm{O}_{2}$ is transported by RBC, $\mathrm{CBC}$ and blood gases are closely related. The present study aimed to establish reference values for arterial blood gases and $C B C$ in cynomolgus monkeys over a wide age range. Blood gases and $C B C$ of arterial blood, collected from 41 female and 21 male anesthetized monkeys, were measured. Age correlated with RBC, HGB and HCT in the CBC. Values differed significantly between males and females in $\mathrm{pCO}_{2}, \mathrm{CO}_{2}$ concentration, $\mathrm{MCV}$ and $\mathrm{MCH}$. The $\mathrm{pH}$ of blood was equivalent to that of humans and $\mathrm{pCO}_{2}$ was more stable, whereas $\mathrm{MCV}$ and $\mathrm{MCH}$ were lower than those in humans. Erythrocytes were smaller and less pigmented than in other Macaca species. Several relationships between gender and age, and blood gases and CBC were identified in cynomolgus monkeys. In conclusion, these reference values will be useful as markers for veterinary applications and in the care and maintenance of these animals.

KEY WORDS: aging, arterial blood gas, complete blood count, cynomolgus monkey, nonhuman primate

Clinical science studies using experimental animal models are important for developing human therapeutics. Animals of the genus Macaca are primates with many physiological and anatomical similarities to humans in comparison to other common laboratory animals, such as mice. Consequently, such nonhuman primates are useful as experimental animal models. The first clinical studies to use nonhuman primates were for the development of polio vaccines in the United States and the former Soviet Union [3, 6]. In Japan, clinical studies in nonhuman primates started when the National Institute of Health established the Tsukuba Primate Research Center in 1978. Even today, clinical studies and official approval of vaccines are conducted at this center using nonhuman primates. Nonhuman primates have thus occupied an important position as an experimental animal model for human systems.

Given this background, clinical evaluation of nonhuman primates is currently conducted based on clinical data from humans and other animals. The target of this study was to establish reference values for cynomolgus monkeys (Macaca fascicularis). Cynomolgus monkeys are Old World monkeys of the genus Macaca, and are useful as an experimental animal model because of their small size and all-season breeding, which is unlike the seasonal breeding of Japanese monkeys ( $M$. fuscata) and rhesus monkeys (M. mulatta).

Reference values for $\mathrm{CBC}$, biochemical parameters, hormone parameters and electrocardiography have been established for cynomolgus monkeys $[1,2,7,16,21,23,28]$. However, the reported blood gases reference values are only for venous samples,

*Correspondence to: Ageyama, N., Tsukuba Primate Research Center, National Institutes of Biomedical Innovation, Health and Nutrition, Hachimandai 1-1, Tsukuba, Ibaraki 305-0843, Japan. e-mail: ageyama@nibiohn.go.jp

(C2017 The Japanese Society of Veterinary Science

This is an open-access article distributed under the terms of the Creative Commons Attribution Non-Commercial No Derivatives (by-ncnd) License. (CC-BY-NC-ND 4.0: https://creativecommons.org/licenses/by-nc-nd/4.0/) 
and arterial blood gas values have not been reported [17]. Blood gas levels are important for advanced medical techniques' such as regenerative medicine, circulatory medicine and innovative drug development $[2,7,9,18]$. In addition, blood gases are important as routine diagnostic parameters. Blood gases are useful for the diagnosis of cardiovascular, respiratory and metabolic diseases. Because arterial blood gases quickly reflect respiratory and circulatory dynamics, they are important for monitoring cardiovascular and respiratory diseases. Arterial blood gas data provide greater advantages than venous blood gas data. In surgical operations, monitoring of blood gases is important for safe and adequate surgical operations because they directly and accurately reflect circulation. Furthermore, examination of preoperative blood gases is vital for safe general anesthesia. From these aspects, arterial blood gas data is valuable and important. The CBC data for cynomolgus monkeys has been reported in previous studies [21, 28]. These reports describe the usefulness of $\mathrm{CBC}$ values, for example, in preoperative examinations and management of cardiovascular disease animals. WBC count is an effective means for deciding whether or not the animal has an infection or inflammatory disease. $\mathrm{HCT}$ and HGB are also correlated with the states of inflammation and dehydration [22]. The $\mathrm{pO}_{2}$ and $\mathrm{pCO}_{2}$ values observed in this study showed significant relationships with $\mathrm{CBC}$ values.

The purpose of this study was to establish reference values for arterial blood gases and CBC in cynomolgus monkeys over a wide age range. The Tsukuba Primate Research Center (National Institutes of Biomedical Innovation, Health and Nutrition) maintains approximately 1700 cynomolgus monkeys in a closed environment for biomedical research. These macaques are used for numerous research projects at this institution, including vaccine, infectious disease, gene therapy, regenerative medicine and aging studies. This colony is the largest primate experimental colony in Japan, and is used by researchers throughout the world for advanced clinical studies $[2,29,30]$.

\section{MATERIALS AND METHODS}

\section{Animals}

This study used 62 cynomolgus monkeys (21 males, 41 females) bred at the Tsukuba Primate Center (Ibaraki, Japan), and was conducted according to the Rules for Animal Care and Management of Tsukuba Primate Center [10], the Guiding Principles for Animal Experiments Using Nonhuman Primates formulated by the Primate Society of Japan [11], and the Institute for Laboratory Animal Research (ILAR) Guide for Care and Use of Laboratory Animals [12]. The Animal Welfare and Animal Care Committee of the National Institutes of Biomedical Innovation Health and Nutrition (NIBIOHN, Osaka, Japan) approved the experimental protocol. All animals were individually housed in stainless-steel cages under the following conditions: temperature, $23-27^{\circ} \mathrm{C}$; humidity, 50-70\%; 12 air changes/hr; 12/12-hr light/dark cycle, and fed $70 \mathrm{~g}$ of commercial monkey chow (CMK-2; CLEA Japan, Inc., Tokyo, Japan) and $200 \mathrm{~g}$ of fruit daily unless otherwise indicated.

The animals had a body weight of 1.1-7.58 kg, and their age was between 1-35 years (Table 1). These represented the distribution of the animals in the facility in regards to gender and age (Fig. 1). We assigned the subject animals to the following age groups: Growth group, $\leq 6$ years $(n=9)$; Adult group, $7-25$ years $(n=43)$; and Aged group, $>26$ years $(n=10)$. These age divisions were determined based on previous research using macaques [4, 20, 29, 30]. Additionally, the Aged group was modified to account for the lifestyle of captive cynomolgus monkeys. While cynomolgus monkeys do not generally live for longer than 26 years in the wild, this age can be achieved in captivity.

\section{Blood sample collection}

Blood was sampled from the femoral or caudal artery of monkeys under ketamine anesthesia (5-10 mg/kg IM, Ketalar; Daiichi Sankyo Propharma, Tokyo, Japan). The collected blood was immediately examined for blood gases. CBC analysis samples were collected in K2-EDTA tubes.

\section{Analysis of blood gases and $C B C$}

Blood gases were determined from whole blood using an autoanalyzer (Rapid Lab 348EX; Siemens, Berlin, Germany). Blood gas analysis included $\mathrm{pH}, \mathrm{pCO}_{2}, \mathrm{pO}_{2}, \mathrm{Na}^{+}, \mathrm{K}^{+}, \mathrm{Ca}^{++}, \mathrm{Cl}^{-}, \mathrm{HCO}_{3}$, base excess $(\mathrm{BE}), \mathrm{CO}_{2}$ concentration $\left(\mathrm{ctCO}_{2}\right), \mathrm{Ca}^{++}(7.4)$ and $\mathrm{O}_{2}$ SAT. CBC was determined using an automated hematology analyzer (KX-21; SYSMEX, Kobe, Japan). CBC analyses included WBC count, RBC count, hemoglobin (HGB), HCT, MCV, MCH, MCHC, platelets (PLT), red blood cell distribution width (RDW), PLT cell distribution width (PDW) and MPV.

\section{Statistical analysis}

Data were divided into age and gender groups. Statistical analyses were performed using a Student's $t$-test and Pearson's product-moment analysis. MacTK version 2.0 analysis software (ESUMI, Tokyo, Japan) was used for statistical analyses. The authors investigated blood gases and CBC parameters using the Pearson's analysis for all age groups. We also analyzed CBC and blood gas parameters using the student's $t$-test between males and females. Finally, we divided the data by age groups and examined all parameters between each group. The data are presented as arithmetic mean values \pm SD. Statistical significance was set at $P<0.05$ and $P<0.01$. 
Table 1. Mean age and weight in male and female cynomolgus monkeys

\begin{tabular}{lccc}
\hline & $\mathrm{n}$ & Weight $(\mathrm{kg}) \pm \mathrm{SD}($ range $)$ & Age \pm SD (range) \\
\hline Male & 21 & $5.14 \pm 1.30(2.78-7.58)$ & $14.4 \pm 9.47(3-32)$ \\
Female & 41 & $3.54 \pm 1.10(1.10-6.18)$ & $17.8 \pm 8.70(1-35)$ \\
\hline
\end{tabular}

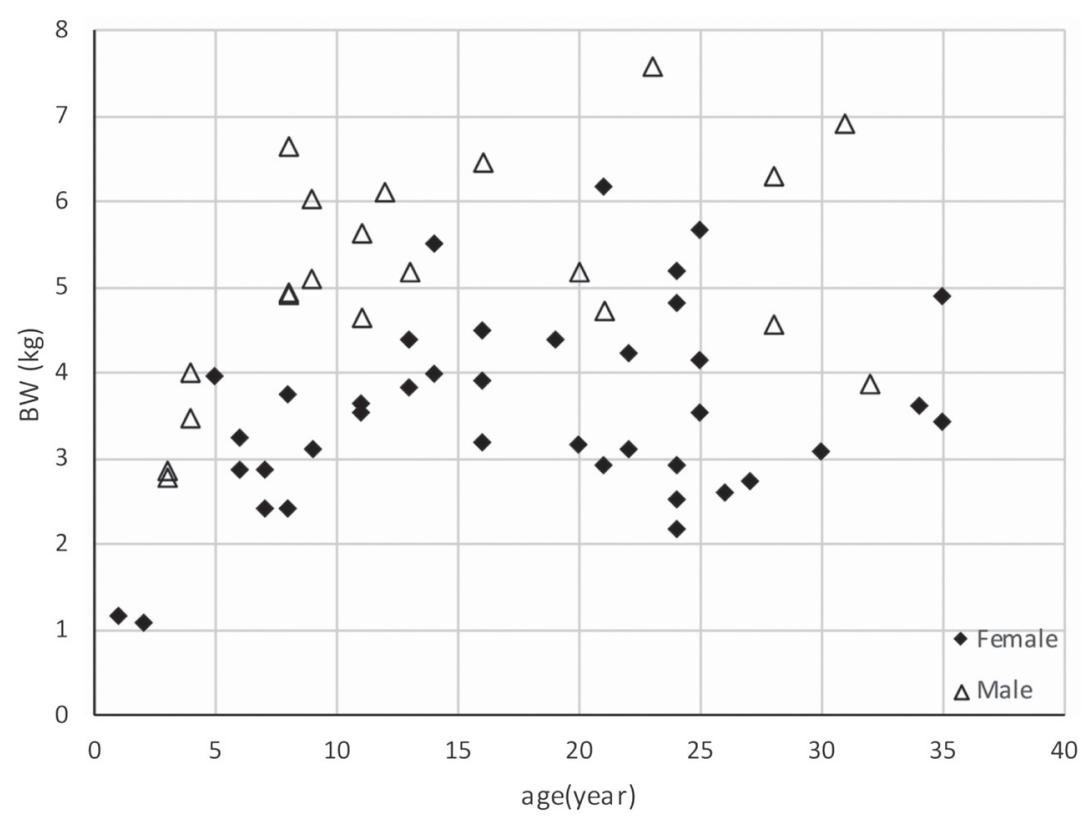

Fig. 1. Distribution of body weight and age in cynomolgus monkeys in this study. Overall, there were broad distributions of both weight and age, but weight tended to be higher in males than females.

\section{RESULTS}

\section{Blood gases}

A significant gender difference was observed for $\mathrm{pCO}_{2}(P<0.01)$, but there was no difference in $\mathrm{pO}_{2}$ levels. Additionally, ctCO differed significantly between the genders $(P<0.05)$ (Table 2$)$. Several parameters differed between the Growth group and the other groups (Table 3). Namely, significant differences in $\mathrm{HCO}_{3}$ and $\mathrm{ctCO}_{2}$ were detected between the Growth group and both Adult and Aged groups, whereas $\mathrm{BE}$ was significantly different between the Growth and Adult groups and $\mathrm{pCO}_{2}$ was significantly different between the Growth and Aged groups (Fig. 2).

\section{$C B C$}

RBC, HGB and HCT were positively correlated with age (Fig. 3). MCV and MCH showed significant gender differences $(P<0.05)$. The Growth group and the other groups showed many significant differences in CBC parameters (Table 5). RBC count, HGB and HCT were significantly different between the Growth and Aged groups $(P<0.01)$. Furthermore, the Adult and Aged groups exhibited significant differences in RBC $(P<0.01)$ and HCT $(P<0.05)$.

\section{DISCUSSION}

This study is the first to report reference values for cynomolgus monkey arterial blood gases. There are some reports of blood gases of cynomolgus monkeys, but only for venous blood gases [17]. Monitoring arterial blood gases is useful for safe general anesthesia and surgical operations, which are also important from the viewpoint of animal welfare. Although reference values for $\mathrm{CBC}$ have already been reported for this species [21], such data have not previously been reported from large-scale experimental facilities like that in this study.

\section{Blood gases}

There was no gender specificity in blood gases (Table 2). Only $\mathrm{pCO}_{2}$ and $\mathrm{ctCO}_{2}$ showed significant gender differences; $\mathrm{pCO}_{2}$ was slightly higher in males than in females. The oxidation tendencies of blood were attributed to differences between male and female cynomolgus monkeys $[19,26]$. This tendency has been confirmed in humans. In rhesus monkeys, BE was reported to be 
Table 2. Comparison of blood gases in male and female cynomolgus monkeys

\begin{tabular}{|c|c|c|c|c|c|c|c|c|c|c|c|c|c|c|}
\hline \multirow{2}{*}{ Items } & \multirow{2}{*}{ Unit } & \multirow{2}{*}{$\mathrm{n}$} & \multirow{2}{*}{ Mean } & \multirow{2}{*}{$\pm \mathrm{SD}$} & \multirow{2}{*}{ CI $90 \%{ }^{\text {a) }}$} & \multicolumn{4}{|c|}{ Male } & \multicolumn{4}{|c|}{ Female } & \multirow{2}{*}{$\begin{array}{c}\text { Gender } \\
\text { Difference }{ }^{b)}\end{array}$} \\
\hline & & & & & & $\mathrm{n}$ & Mean & $\pm \mathrm{SD}$ & CI $90 \%$ a) & $\mathrm{n}$ & Mean & $\pm \mathrm{SD}$ & CI 90\% a) & \\
\hline $\mathrm{pH}$ & & 55 & 7.40 & 0.05 & $7.39-7.41$ & 20 & 7.40 & 0.06 & $7.38-7.42$ & 35 & 7.40 & 0.05 & $7.38-7.41$ & \\
\hline $\mathrm{pCO}_{2}$ & $\mathrm{mmHg}$ & 55 & 36.24 & 4.23 & $35.30-37.18$ & 20 & 38.57 & 2.89 & $37.45-39.69$ & 35 & 34.91 & 4.32 & $33.67-36.14$ & ** \\
\hline $\mathrm{pO}_{2}$ & $\mathrm{mmHg}$ & 55 & 90.53 & 9.19 & $88.49-92.57$ & 20 & 88.36 & 6.10 & $85.99-90.72$ & 35 & 91.78 & 10.44 & $88.79-94.76$ & \\
\hline $\mathrm{Na}^{+}$ & $\mathrm{mmol} / \mathrm{l}$ & 55 & 148.02 & 3.21 & $147.31-148.73$ & 20 & 149.00 & 3.15 & $147.78-150.22$ & 35 & 147.46 & 3.15 & $146.56-148.36$ & \\
\hline $\mathrm{K}^{+}$ & $\mathrm{mmol} / \mathrm{l}$ & 55 & 3.70 & 0.40 & $3.61-3.79$ & 20 & 3.82 & 0.32 & $3.69-3.94$ & 35 & 3.64 & 0.43 & $3.52-3.76$ & \\
\hline $\mathrm{Cl}^{-}$ & $\mathrm{mmol} / l$ & 34 & 107.97 & 2.25 & $107.34-108.61$ & 12 & 108.75 & 1.60 & $107.92-109.58$ & 22 & 107.55 & 2.46 & $106.64-108.45$ & \\
\hline $\mathrm{Ca}^{++}$ & $\mathrm{mmol} / l$ & 55 & 1.20 & 0.07 & $1.18-1.21$ & 20 & 1.21 & 0.07 & $1.19-1.24$ & 35 & 1.19 & 0.06 & $1.17-1.20$ & \\
\hline $\mathrm{HCO}_{3}$ & $\mathrm{mmol} / \mathrm{l}$ & 55 & 22.79 & 3.33 & $22.05-23.52$ & 20 & 23.88 & 3.65 & $22.47-25.29$ & 35 & 22.16 & 3.02 & $21.30-23.02$ & \\
\hline $\mathrm{BE}$ & $\mathrm{mmol} / l$ & 55 & -2.16 & 4.09 & $-3.07--1.25$ & 20 & -0.86 & 4.37 & $-2.55-0.84$ & 35 & -2.90 & 3.78 & $-3.98--1.82$ & \\
\hline $\operatorname{ctCO}_{2}$ & $\mathrm{mmol} / l$ & 55 & 23.20 & 3.98 & $22.32-24.09$ & 20 & 24.88 & 4.02 & $23.32-26.43$ & 35 & 22.25 & 3.67 & $21.20-23.30$ & * \\
\hline $\mathrm{Ca}^{++}(7.4)$ & $\mathrm{mmol} / \mathrm{l}$ & 55 & 1.20 & 0.07 & $1.18-1.21$ & 20 & 1.21 & 0.07 & $1.19-1.24$ & 35 & 1.18 & 0.06 & $1.17-1.20$ & \\
\hline AnGap & $\mathrm{mmol} / \mathrm{l}$ & 32 & 16.22 & 3.59 & $15.18-17.27$ & 12 & 15.92 & 2.86 & $14.43-17.40$ & 20 & 16.41 & 4.02 & $14.85-17.96$ & \\
\hline $\mathrm{O}_{2} \mathrm{SAT}$ & $\%$ & 55 & 96.80 & 0.86 & $96.61-96.99$ & 20 & 96.68 & 0.64 & $96.43-96.92$ & 35 & 96.87 & 0.97 & $96.59-97.15$ & \\
\hline
\end{tabular}

a) CI $90 \%=90 \%$ confidence interval; b) Significant gender difference. $* P<0.05 ; * * P<0.01$.

Table 3. Comparison of blood gases between age groups of cynomolgus monkeys

\begin{tabular}{|c|c|c|c|c|c|c|c|c|c|c|c|}
\hline \multirow{2}{*}{ Items } & \multirow{2}{*}{ Unit } & \multicolumn{2}{|c|}{ 0-6 y (Growth) } & \multicolumn{2}{|c|}{$7-25$ y (Adult) } & \multicolumn{2}{|c|}{$>26$ y (Aged) } & \multicolumn{2}{|c|}{ Growth vs } & \multirow{2}{*}{$\begin{array}{c}\text { Adult vs } \\
\text { Aged }\end{array}$} & \multirow{2}{*}{ Pearson's correlation } \\
\hline & & Mean & $\pm \mathrm{SD}$ & Mean & $\pm \mathrm{SD}$ & Mean & $\pm \mathrm{SD}$ & Adult & Aged & & \\
\hline $\mathrm{pH}$ & & 7.37 & 0.06 & 7.41 & 0.05 & 7.39 & 0.06 & & & & 0.12 \\
\hline $\mathrm{pCO}_{2}$ & $\mathrm{mmHg}$ & 34.98 & 4.80 & 35.77 & 4.18 & 39.43 & 2.13 & & $*$ & $* *$ & 0.27 \\
\hline $\mathrm{pO}_{2}$ & $\mathrm{mmHg}$ & 93.64 & 7.55 & 90.20 & 9.66 & 88.80 & 8.87 & & & & -0.13 \\
\hline $\mathrm{Na}^{+}$ & $\mathrm{mmol} / \mathrm{l}$ & 147.00 & 2.55 & 148.32 & 3.30 & 147.78 & 3.49 & & & & 0.01 \\
\hline $\mathrm{K}^{+}$ & $\mathrm{mmol} / \mathrm{l}$ & 3.63 & 0.56 & 3.69 & 0.35 & 3.84 & 0.45 & & & & 0.15 \\
\hline $\mathrm{Cl}^{-}$ & $\mathrm{mmol} / \mathrm{l}$ & 109.25 & 1.89 & 108.17 & 2.10 & 106.33 & 2.50 & & & & -0.37 \\
\hline $\mathrm{Ca}^{++}$ & $\mathrm{mmol} / \mathrm{l}$ & 1.21 & 0.06 & 1.19 & 0.07 & 1.21 & 0.08 & & & & 0.02 \\
\hline $\mathrm{HCO}_{3}$ & $\mathrm{mmol} / \mathrm{l}$ & 20.63 & 2.28 & 23.08 & 3.32 & 23.74 & 3.66 & $*$ & $*$ & & 0.22 \\
\hline $\mathrm{BE}$ & $\mathrm{mmol} / \mathrm{l}$ & -4.77 & 2.95 & -1.81 & 4.08 & -1.00 & 4.42 & $*$ & & & 0.23 \\
\hline $\operatorname{ctCO}_{2}$ & $\mathrm{mmol} / \mathrm{l}$ & 20.77 & 2.82 & 23.37 & 4.01 & 24.97 & 4.00 & $*$ & $*$ & & 0.26 \\
\hline $\mathrm{Ca}^{++}(7.4)$ & $\mathrm{mmol} / \mathrm{l}$ & 1.19 & 0.07 & 1.20 & 0.07 & 1.20 & 0.06 & & & & 0.06 \\
\hline AnGap & $\mathrm{mmol} / \mathrm{l}$ & 16.80 & 3.39 & 16.05 & 3.79 & 16.45 & 3.49 & & & & 0.14 \\
\hline $\mathrm{O}_{2} \mathrm{SAT}$ & $\%$ & 96.86 & 0.87 & 96.84 & 0.89 & 96.60 & 0.83 & & & & -0.10 \\
\hline
\end{tabular}

$* P<0.05 ; * * P<0.01$.

Table 4. Comparison of $\mathrm{CBC}$ parameters in male and female cynomolgus monkeys

\begin{tabular}{|c|c|c|c|c|c|c|c|c|c|c|c|c|c|c|}
\hline \multirow{2}{*}{ Items } & \multirow{2}{*}{ Unit } & \multirow{2}{*}{$\mathrm{n}$} & \multirow{2}{*}{ Mean } & \multirow{2}{*}{$\pm \mathrm{SD}$} & \multirow{2}{*}{ CI $90 \%$ a) } & \multicolumn{4}{|c|}{ Male } & \multicolumn{4}{|c|}{ Female } & \multirow{2}{*}{$\begin{array}{c}\text { Gender } \\
\text { Difference }^{\text {b) }}\end{array}$} \\
\hline & & & & & & $\mathrm{n}$ & Mean & $\pm \mathrm{SD}$ & CI $90 \%$ a) & $\mathrm{n}$ & Mean & $\pm \mathrm{SD}$ & CI $90 \%$ a) & \\
\hline WBC & $\times 10^{2} / \mu l$ & 62 & 83.82 & 28.20 & $77.93-89.71$ & 21 & 82.52 & 29.93 & $71.26-93.79$ & 41 & 84.49 & 27.64 & $77.22-91.76$ & \\
\hline $\mathrm{RBC}$ & $\times 10^{4} / \mu l$ & 62 & 637.24 & 91.06 & $618.22-656.26$ & 21 & 613.95 & 85.35 & 581.83-646.08 & 41 & 649.17 & 92.59 & $624.82-673.52$ & \\
\hline HGB & $\mathrm{g} / \mathrm{d} l$ & 62 & 12.48 & 1.65 & $12.13-12.82$ & 21 & 12.46 & 1.49 & 11.90-13.02 & 41 & 12.49 & 1.74 & $12.03-12.95$ & \\
\hline $\mathrm{HCT}$ & $\%$ & 62 & 43.08 & 5.33 & 41.97-44.19 & 21 & 42.59 & 5.17 & $40.64-44.54$ & 41 & 43.33 & 5.45 & $41.90-44.77$ & \\
\hline $\mathrm{MCV}$ & $\mathrm{f} l$ & 62 & 67.95 & 4.49 & $67.01-68.89$ & 21 & 69.76 & 5.21 & $67.80-71.72$ & 41 & 67.02 & 3.81 & $66.02-68.02$ & * \\
\hline $\mathrm{MCH}$ & $p g$ & 62 & 19.70 & 1.87 & 19.31-20.09 & 21 & 20.43 & 1.75 & $19.77-21.09$ & 41 & 19.32 & 1.83 & $18.84-19.81$ & $*$ \\
\hline $\mathrm{MCHC}$ & $\mathrm{g} / \mathrm{d} l$ & 62 & 28.97 & 1.68 & $28.62-29.32$ & 21 & 29.30 & 1.22 & $28.84-29.76$ & 41 & 28.80 & 1.86 & $28.32-29.29$ & \\
\hline PLT & $\times 10^{4} / \mu l$ & 62 & 31.81 & 9.34 & $29.86-33.76$ & 21 & 31.10 & 11.16 & $26.91-35.30$ & 41 & 32.17 & 8.39 & $29.96-34.37$ & \\
\hline RDW & $\mathrm{fl}$ & 62 & 32.24 & 9.83 & $30.19-34.30$ & 21 & 32.72 & 4.91 & $30.87-34.57$ & 41 & 33.70 & 4.47 & $32.53-34.88$ & \\
\hline PDW & $\mathrm{fl}$ & 60 & 11.73 & 2.25 & $11.25-12.21$ & 20 & 11.63 & 2.89 & $10.51-12.74$ & 40 & 11.78 & 1.89 & $11.28-12.28$ & \\
\hline MPV & $\mathrm{f} l$ & 60 & 9.78 & 1.18 & $9.53-10.03$ & 20 & 9.68 & 1.32 & $9.17-10.19$ & 40 & 9.83 & 1.12 & $9.53-10.13$ & \\
\hline
\end{tabular}

a) CI $90 \%=90 \%$ confidence interval; b) Significant gender difference. $* P<0.05$. 
A

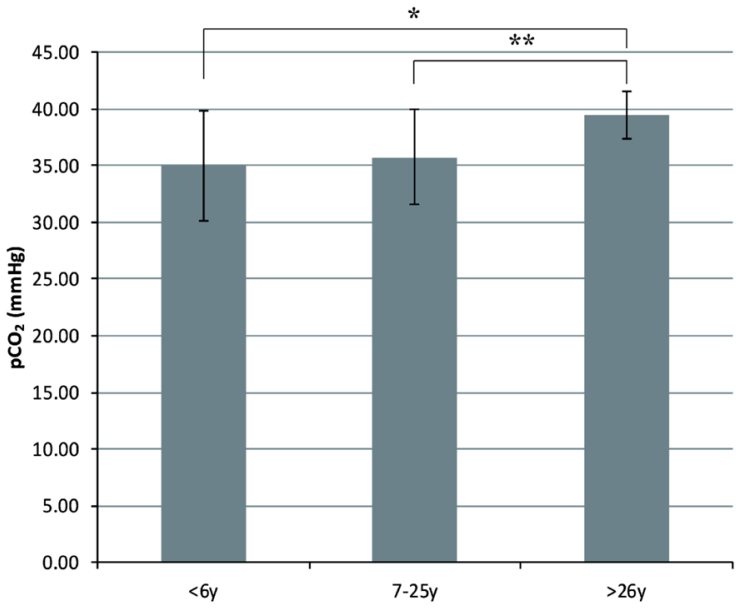

C

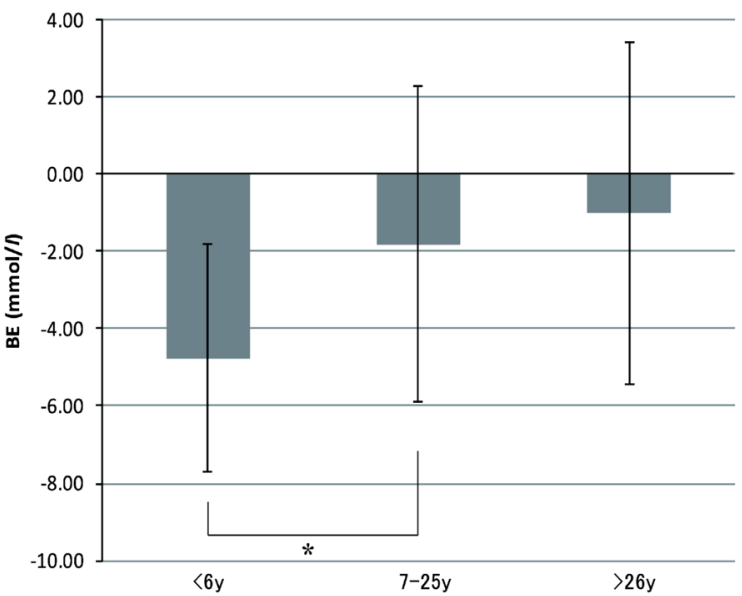

B

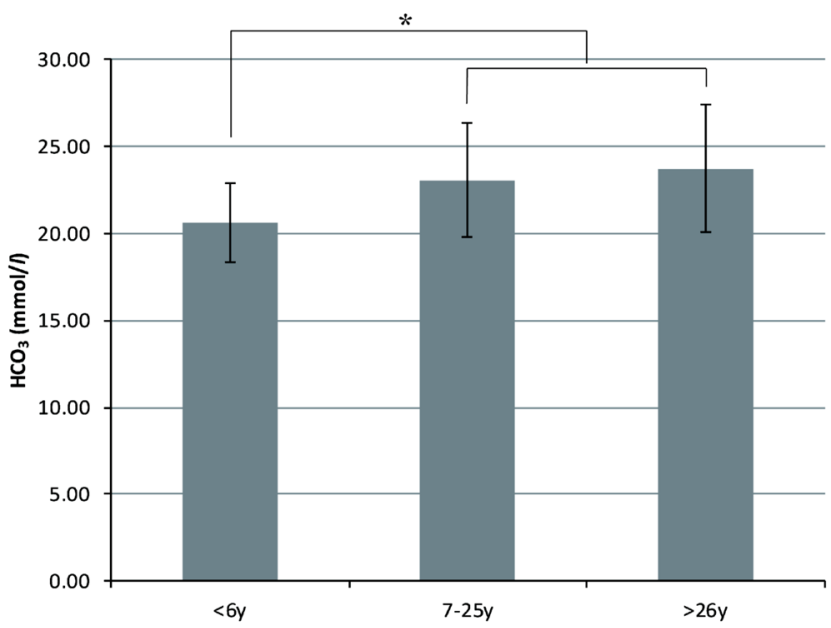

D

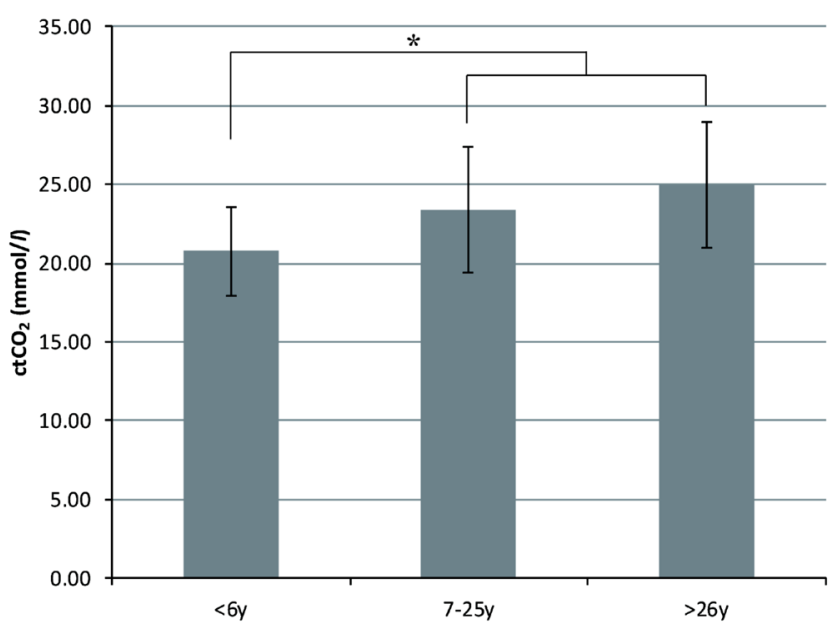

Fig. 2. Blood gas parameters plotted according to age. The $\mathrm{pCO}_{2}, \mathrm{HCO}_{3}$ and $\mathrm{BE}$ showed significant differences. The Aged group showed an increase in $\mathrm{pCO}_{2}(\mathrm{~A})$, and $\mathrm{pCO}_{2}$ increased in an age-dependent manner. The Growth group showed significant differences in ctCO and $\mathrm{HCO}_{3}$ compared to the other groups (B, D). The BE increased in an age-dependent manner, and the Growth and Adult groups were significantly different from each other $(\mathrm{C})$. Decreased BE indicates alkalosis (C).

lower than in humans. From these findings, the reference value for BE is approximately $-3.09 \mathrm{mmol} / \mathrm{l}$ in female cynomolgus monkeys (Table 2 and Fig. 2C). Values of pH were stable and consistent with that of other primates, including humans [15]. On the other hand, rhesus monkeys show higher $\mathrm{pH}$ values than those of humans $[9,18]$. Cynomolgus monkeys were found to show $\mathrm{pH}$ values closer to humans than to rhesus monkeys. In addition, $\mathrm{pCO}_{2}$ was lower in cynomolgus monkeys than in humans, whereas $\mathrm{pO}_{2}$ was similar to that observed in humans [15]. The $\mathrm{pCO}_{2}$ of cynomolgus monkeys resembled that of rhesus monkeys, which suggests close values within the genus Macaca [18].

Significant age differences were observed for $\mathrm{pCO}_{2}, \mathrm{HCO}_{3}$ and $\mathrm{ctCO}_{2}$, which might be attributable to differences in metabolism because the circulatory system has an age-dependent decline (Fig. 2A, 2B and 2D) [14, 19]. However, this range is within the physiological value of humans. $\mathrm{Na}^{+}$and $\mathrm{K}^{+}$values in both genders were higher than those in humans or rhesus monkeys [15, 18], and $\mathrm{Cl}^{-}$showed slightly higher values compared to those in rhesus monkeys (Table 2). $\mathrm{Na}^{+}$is thought to exhibit a tendency toward high levels in the genus Macaca, because the levels found in rhesus monkeys were higher than in humans. $\mathrm{Cl}^{-}$was shown here to be slightly higher than in humans. It should be noted that our experimental groups were composed of nutritionally controlled individuals, and external factors such as the excessive intake of salt were controlled for. Rhesus monkeys showed a similar tendency, and the genus Macaca are reported to show higher $\mathrm{Na}^{+}$and $\mathrm{Cl}^{-}$compared to humans $[15,18]$. Additionally, $\mathrm{Ca}^{++}$ was higher than in rhesus monkeys $[15,18]$. The anion gap was slightly lower in cynomolgus monkeys $(16.22 \pm 3.59 \mathrm{mmol} / l)$ compared to rhesus monkeys $(17.21 \pm 4.53 \mathrm{mmol} / t)$, but higher than in humans $(12 \pm 2 \mathrm{mmol} / t)[15] . \mathrm{HCO}_{3}$ in the present study, as well as in previous reports for rhesus monkeys, showed a trend similar to the findings in humans [18]. Thus, the high levels of $\mathrm{Na}^{+}$are thought to cause the high anion gap in genus Macaca. High $\mathrm{Na}^{+}$can be caused by conditions such as dehydration, aldosteronism, Cushing's syndrome and other disorders; however, these conditions were not observed in our laboratory findings. The high $\mathrm{Na}^{+}$level in macaques thus appears to be of physiological value. The high anion gap observed in females might be due to their low $\mathrm{HCO}_{3}$ values (Table 2). One reason for the low $\mathrm{HCO}_{3}$ is that acids carrying a negative charge, such as metabolites of 
A

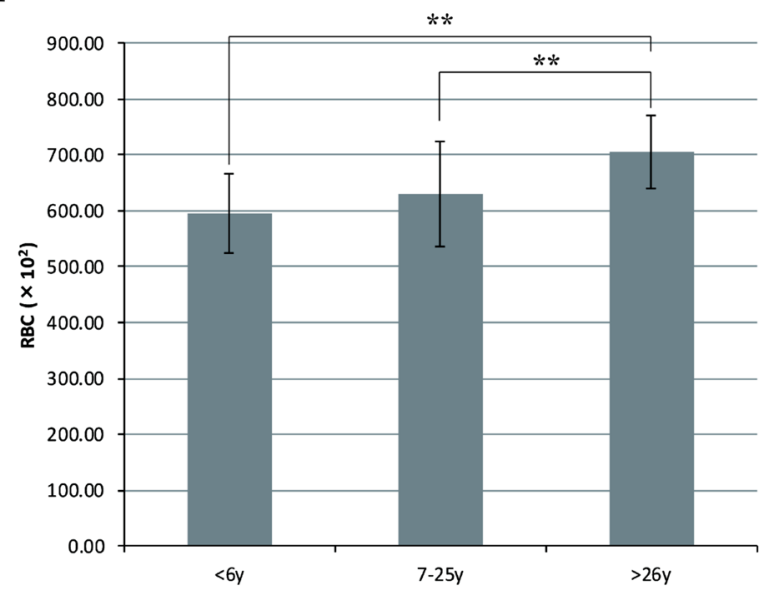

$\mathrm{B}$

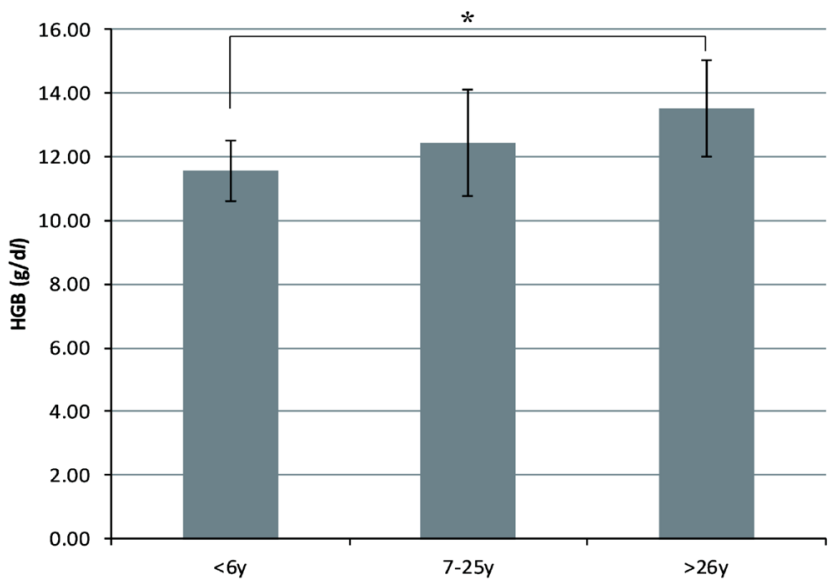

$\mathrm{C}$

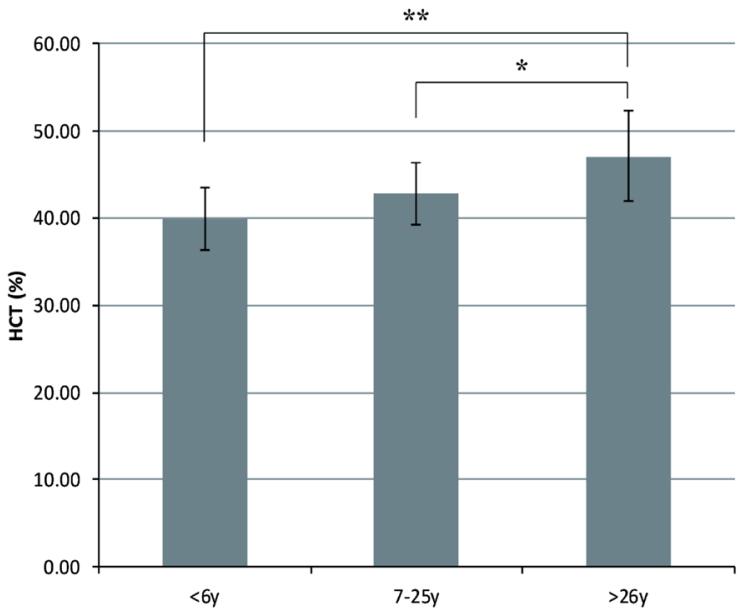

Fig. 3. Age-related changes in blood parameters. RBC count (A), HGB (B) and HCT (C) increased in an age-dependent manner, and several differences were observed between the Aged and other groups.

Table 5. Comparison of $\mathrm{CBC}$ parameters between age groups of cynomolgus monkeys

\begin{tabular}{|c|c|c|c|c|c|c|c|c|c|c|c|}
\hline \multirow{2}{*}{ Items } & \multirow{2}{*}{ Unit } & \multicolumn{2}{|c|}{ 0-6 y (Growth) } & \multicolumn{2}{|c|}{$7-25$ y (Adult) } & \multicolumn{2}{|c|}{$>26$ y (Aged) } & \multicolumn{2}{|c|}{ Growth vs } & \multirow{2}{*}{$\frac{\text { Adult vs }}{\text { Aged }}$} & \multirow{2}{*}{ Pearson's correlation } \\
\hline & & Mean & $\pm \mathrm{SD}$ & Mean & $\pm \mathrm{SD}$ & Mean & $\pm \mathrm{SD}$ & Adult & Aged & & \\
\hline WBC & $\times 10^{2} / \mu l$ & 93.22 & 27.21 & 83.30 & 29.75 & 77.60 & 21.70 & & & & -0.06 \\
\hline $\mathrm{RBC}$ & $\times 10^{4} / \mu l$ & 595.56 & 72.13 & 630.16 & 92.85 & 705.20 & 65.09 & & $* *$ & $* *$ & 0.50 \\
\hline HGB & $\mathrm{g} / \mathrm{d} l$ & 11.58 & 0.95 & 12.42 & 1.68 & 13.53 & 1.53 & & $* *$ & & 0.49 \\
\hline $\mathrm{HCT}$ & $\%$ & 39.88 & 3.55 & 42.83 & 5.23 & 47.06 & 5.03 & & $* *$ & * & 0.53 \\
\hline $\mathrm{MCV}$ & $\mathrm{f} l$ & 67.28 & 4.27 & 68.36 & 4.60 & 66.77 & 4.33 & & & & -0.12 \\
\hline $\mathrm{MCH}$ & $p \mathrm{~g}$ & 19.56 & 1.51 & 19.84 & 1.96 & 19.22 & 1.79 & & & & -0.10 \\
\hline $\mathrm{MCHC}$ & $\mathrm{g} / \mathrm{d} l$ & 29.07 & 1.15 & 29.00 & 1.89 & 28.76 & 1.04 & & & & -0.02 \\
\hline PLT & $\times 10^{4} / \mu l$ & 33.49 & 7.55 & 31.87 & 8.58 & 30.02 & 13.82 & & & & 0.04 \\
\hline RDW & $\mathrm{f} l$ & 31.57 & 7.57 & 33.31 & 4.05 & 35.25 & 3.05 & & & & 0.28 \\
\hline PDW & $\mathrm{f} l$ & 11.15 & 1.62 & 11.71 & 2.33 & 12.26 & 2.39 & & & & 0.08 \\
\hline MPV & $\mathrm{f} l$ & 9.51 & 0.69 & 9.80 & 1.27 & 9.91 & 1.16 & & & & 0.04 \\
\hline
\end{tabular}

$* P<0.05 ; * * P<0.01$.

salicylic acid, ketone bodies, lactic acid, sulfuric acid, methanol and ethylene glycol, are utilized in the consumption of $\mathrm{HCO}_{4}^{-}$. However, the results suggest that these conditions were not observed in the present study, and further characterization of this finding is necessary. In this study, $\mathrm{HCO}_{3}$ showed clear differences between the Growth and the other groups (Fig. 2B). However, significant differences were not observed in the Pearson's analysis across all age groups (Table 3). This might indicate that insufficient sample numbers were employed. This study used a large number of cynomolgus monkeys ( $\mathrm{n}=62$ ), and it seems that this 
number is sufficient to determine standard values (Table 1 and Fig. 1). However, there is a need for validation at other institutes in the future.

\section{$C B C$}

Comparing the $\mathrm{CBC}$ values of this study with those of previous reports for cynomolgus monkeys, similar results were evident for many parameters such as RBC count, $\mathrm{HGB}, \mathrm{HCT}, \mathrm{MCV}, \mathrm{MCH}$ and $\mathrm{MCHC}$ [21].

In this study, RBC count, HGB and HCT were slightly higher in females than in males (Table 4). In general, these low values in females have been attributed to menstruation $[15,21]$. The high values for female RBC count in this study were attributed to less variation in the age of males compared to females. This is characteristic of many breeding colonies, where the goal is to achieve large litter sizes. Our study did not show significant differences between genders in RBC, HGB and HCT. The use of larger sample numbers is expected to attenuate these differences. MCV and MCH were lower than in humans. In reports of rhesus monkeys, MCV was lower than in humans. Therefore, all Macaca RBC levels are thought to be lower than that in humans [15]. MCH has been reported to show significantly lower values in cynomolgus monkeys than in humans, and a low value compared with rhesus monkeys [9, 18, 24, 25]. RBCs in cynomolgus monkeys thus appear to be less pigmented (Table 5). RBCs become more pigmented with aging. A similar phenomenon can be seen in human blood analysis. The parameters of RBC count, HGB and HCT increased in an age-dependent manner (Fig. 3). Similar results have also been observed in other monkeys [5, 13, 22, 27].

\section{Relationship between blood gases and CBC}

Blood gas and $\mathrm{CBC}$ values are related to the circulatory system, which is closely related to aging, dehydration, and inflammatory diseases $[8,22]$. Since $\mathrm{O}_{2}$ is carried by $\mathrm{RBC}, \mathrm{pO}_{2}$ is closely related to $\mathrm{RBC}$ count, and declines in these values are important factors in assessing physiological functions, such as erythropoietin production in the kidney.

There is no aging effect on $\mathrm{pO}_{2}$ (Table 3). However, HCT, HGB and RGB (which are related to $\mathrm{pO}_{2}$ ) increase with age (Fig. 3). In humans, these values decrease with age [8]. Previous research showed that the RBC value increased in aged macaques, suggesting a relationship with maintenance of $\mathrm{pO}_{2}[5,13,22]$. On the other hand, $\mathrm{CO}_{2}$ is carried by serum rather than $\mathrm{RBC}$. It is already known that in cynomolgus monkeys circulatory function decreases with age. Therefore, $\mathrm{pCO}_{2}$ responds to circulatory dynamics and increases with age (Fig. 2A) [14].

The measurements obtained in this study should prove useful as reference values for blood gases and CBC parameters in cynomolgus monkeys over a wide range of ages. These reference values will be useful as markers for veterinary applications and in the care and maintenance of these animals.

ACKNOWLEDGMENTS. We wish to thank Hiromi Ogawa for the handling and care of monkeys. We are grateful to Keiko Ohto and Mayuko Tanaka for the excellent technical assistance. This work was supported by JSPS KAKENHI Grant Numbers 17790515 , 24615009, and 15K07789, as well as grants from the Japan Agency for Medical Research and Development.

\section{REFERENCES}

1. Ageyama, N., Seki, Y., Muneyuki, K., Kandori, A., Tsukada, K. and Terao, K. 2007. Application of magnetocardiography for non-human primate arrhythmia models. The Journal of Japan Biomagnetism and Bioelectromagnetics Society 20: 90-91.

2. Bashuda, H., Kimikawa, M., Seino, K., Kato, Y., Ono, F., Shimizu, A., Yagita, H., Teraoka, S. and Okumura, K. 2005. Renal allograft rejection is prevented by adoptive transfer of anergic T cells in nonhuman primates. J. Clin. Invest. 115: 1896-1902. [Medline] [CrossRef]

3. Blume, S. and Geesink, I. 2000. A brief history of polio vaccines. Science 288: 1593-1594. [Medline] [CrossRef]

4. Ekanayake, D. K., Horadagoda, N. U., Sanjeevani, G. K., Arulkanthan, A., Gunatilake, K. A. and Dittus, W. P. 2003. Hematology of a natural population of toque macaques (Macaca sinica) at polonnaruwa, Sri Lanka. Am. J. Primatol. 61: 13-28. [Medline] [CrossRef]

5. Fowler, M. E. and Miller, R. E. 2003. Reference range of clinical test items. Non Ape Primetes. pp. 357-359, 381-384. In: Zoo and Wild Animal Medicine, 5th ed. (Murray E. Fowler R. Eric Miller, eds.), Elsevier, Amsterdum.

6. Furesz, J. 2006. Developments in the production and quality control of poliovirus vaccines -- historical perspectives. Biologicals 34: 87-90. [Medline] [CrossRef]

7. Goto, Y., Hiramatsu, Y., Ageyama, N., Sato, S., Kanemoto, S., Sato, Y. and Sakakibara, Y. 2014. Cardiopulmonary bypass induces recruitment of bone marrow-derived leukocytes to the lungs in monkeys. Ann. Thorac. Surg. 97: 617-622. [Medline] [CrossRef]

8. Guralnik, J. M., Eisenstaedt, R. S., Ferrucci, L., Klein, H. G. and Woodman, R. C. 2004. Prevalence of anemia in persons 65 years and older in the United States: evidence for a high rate of unexplained anemia. Blood 104: 2263-2268. [Medline] [CrossRef]

9. Hom, G. J., Bach, T. J., Carroll, D., Forrest, M. J., Mariano, M. A., Trainor, C. E., Wang, P. R. and MacIntyre, D. E. 1999. Comparison of Cardiovascular Parameters and/or Serum Chemistry and Hematology Profiles in Conscious and Anesthetized Rhesus Monkeys (Macaca mulatta). Contemp. Top. Lab. Anim. Sci. 38: 60-64. [Medline]

10. Honjo, S. 1985. The Japanese Tsukuba Primate Center for Medical Science (TPC): an outline. J. Med. Primatol. 14: 75-89. [Medline]

11. Honjo, S. 1986. Guiding Principles for animal experiments using nonhuman primates. Primate Rep. 2: 111-113. [CrossRef]

12. Institute for Laboratory Animal Research. 2011. Guide for the care and use of laboratory animals. National Academies Press, Washington, D.C.

13. Ihrig, M., Tassinary, L. G., Bernacky, B. and Keeling, M. E. 2001. Hematologic and serum biochemical reference intervals for the chimpanzee (Pan troglodytes) categorized by age and sex. Comp. Med. 51: 30-37. [Medline]

14. Ishizaka, T., Yoshimatsu, Y., Ozawa, M., Kimotsuki, T., Takasaki, W., Manabe, S. and Yasuda, M. 2009. Age-related differences of QT interval and autonomic nervous system activity in female cynomolgus monkeys. J. Pharmacol. Toxicol. Methods 60: 288-295. [Medline] [CrossRef]

15. Kim, E. B., Susan, M. B., Scott, B. and Heddwen, L. B. 2006. Ganong's Review of Medical Physiology, 22th ed., McGraw-Hill Education, New York. 
16. Koie, H., Ageyama, N., Ono, F., Kanayama, K., Sakai, T. and Sankai, T. 2005. Echocardiographic diagnosis of muscular ventricular septal defect in a cynomolgus monkey (Macaca fascicularis). Contemp. Top. Lab. Anim. Sci. 44: 26-28. [Medline]

17. Lee, J. I., Hong, S. H., Lee, S. J., Kim, Y. S. and Kim, M. C. 2003. Immobilization with ketamine $\mathrm{HCl}$ and tiletamine-zolazepam in cynomolgus monkeys. J. Vet. Sci. 4: 187-191. [Medline]

18. Lee, J. I., Shin, J. S., Lee, J. E., Jung, W. Y., Lee, G., Kim, M. S., Park, C. G. and Kim, S. J. 2012. Reference values of hematology, chemistry, electrolytes, blood gas, coagulation time, and urinalysis in the Chinese rhesus macaques (Macaca mulatta). Xenotransplantation 19: 244-248. [Medline] [CrossRef]

19. Qiu, H., Depre, C., Ghosh, K., Resuello, R. G., Natividad, F. F., Rossi, F., Peppas, A., Shen, Y. T., Vatner, D. E. and Vatner, S. F. 2007. Mechanism of gender-specific differences in aortic stiffness with aging in nonhuman primates. Circulation 116: 669-676. [Medline] [CrossRef]

20. Sato, A., Fairbanks, L. A., Lawson, T. and Lawson, G. W. 2005. Effects of age and sex on hematologic and serum biochemical values of vervet monkeys (Chlorocebus aethiops sabaeus). Contemp. Top. Lab. Anim. Sci. 44: 29-34. [Medline]

21. Schuurman, H. J. and Smith, H. T. 2005. Reference values for clinical chemistry and clinical hematology parameters in cynomolgus monkeys. Xenotransplantation 12: 72-75. [Medline] [CrossRef]

22. Silver, A. J. 1990. Aging and risks for dehydration. Cleve. Clin. J. Med. 57: 341-344. [Medline] [CrossRef]

23. Sleeper, M. M., Gaughan, J. M., Gleason, C. R. and Burkett, D. E. 2008. Echocardiographic reference ranges for sedated healthy cynomolgus monkeys (Macaca fascicularis). J. Am. Assoc. Lab. Anim. Sci. 47: 22-25. [Medline]

24. Smucny, D. A., Allison, D. B., Ingram, D. K., Roth, G. S., Kemnitz, J. W., Kohama, S. G., Lane, M. A., Black A., Primate Aging Database Working Group. 2001. Changes in blood chemistry and hematology variables during aging in captive rhesus macaques (Macaca mulatta). J. Med. Primatol. 30: 161-173. [Medline] [CrossRef]

25. Smucny, D. A., Allison, D. B., Ingram, D. K., Roth, G. S., Kemnitz, J. W., Kohama, S. G., Lane, M. A. and Black, A. 2004. Changes in blood chemistry and hematology variables during aging in captive rhesus macaques (Macaca mulatta). J Med Primatol 30:161-173, 2001. J. Med. Primatol. 33: 48-54. [Medline] [CrossRef]

26. Tatsumi, K., Hannhart, B., Pickett, C. K., Weil, J. V. and Moore, L. G. 1991. Influences of gender and sex hormones on hypoxic ventilatory response in cats. J. Appl. Physiol. 71: 1746-1751. [Medline]

27. Videan, E. N., Fritz, J. and Murphy, J. 2008. Effects of aging on hematology and serum clinical chemistry in chimpanzees (Pan troglodytes). Am. J. Primatol. 70: 327-338. [Medline] [CrossRef]

28. Yoshida, T. and Fujimoto, K. 2006. Cynomolgus Monkeys as a Medical Science Research Resources-Ikagaku Kenkyu Shigen Toshiteno Kanikui Zaru. 1st ed., Springer Japan, Tokyo. (in Japanese).

29. Yoshioka, T., Ageyama, N., Shibata, H., Yasu, T., Misawa, Y., Takeuchi, K., Matsui, K., Yamamoto, K., Terao, K., Shimada, K., Ikeda, U., Ozawa, K. and Hanazono, Y. 2005. Repair of infarcted myocardium mediated by transplanted bone marrow-derived CD $34^{+}$stem cells in a nonhuman primate model. Stem Cells 23: 355-364. [Medline] [CrossRef]

30. Yuki, Y., Nochi, T., Harada, N., Katakai, Y., Shibata, H., Mejima, M., Kohda, T., Tokuhara, D., Kurokawa, S., Takahashi, Y., Ono, F., Kozaki, S., Terao, K., Tsukada, H. and Kiyono, H. 2010. In vivo molecular imaging analysis of a nasal vaccine that induces protective immunity against botulism in nonhuman primates. J. Immunol. 185: 5436-5443. [Medline] [CrossRef] 